\title{
The design and integration of ESP content in an upper-intermediate online course
}

\author{
Ana Gimeno Sanz ${ }^{1}$ \\ Universidad Politécnica de Valencia
}

Antonio Martínez Sáez

Universidad Autónoma de Madrid

\begin{abstract}
Language instructors who adopt the role of materials writers in order to provide their students with more accurate tailor-made learning resources usually start by closely examining their learners' needs and demands, as well as the distinctive features of the teaching context or situation in which those materials are going to be implemented. This idea is especially relevant when the linguistic resources are developed to be used by future engineers who access them to practice and learn a language that will have a dominant presence in their future working environment. This is a fact that encouraged the authors to design an online upper-intermediate level English course which incorporates relevant language resources directly linked to the disciplines and content covered by their students' university undergraduate degrees. The course is known as the InGenio FCE Online Course \& Tester (Universitat Politècnica de València, 2011).
\end{abstract}

The article illustrates how language instructors try to explore and find new ways, methods, typologies of exercises, and techniques which might help them create, promote, and implement learning systems capable of fostering an integral communicative competence and make the entire learning process more dynamic and attractive. A specific case study dealing with students who seek to make the most of combining Computer-Assisted Language Learning and English for Specific Purposes is described and analysed here.

The reader is presented with a description of the steps that were taken to design innovative and engaging online courseware to cater for the learners' specific needs and the conclusions that have arisen from conducting a survey to analyse student perceptions and expectations

1 Corresponding author - Universidad Politécnica de Valencia, Departamento de Lingüística Aplicada, Valencia (Spain). Email: agimeno@upvnet.upv.es 
prior to and after completing the said online course.

Keywords: ESP content; online language learning; courseware design; InGenio authoring tool; learner satisfaction

\section{Introduction}

The research presented in this article is based on part of the work conducted throughout the stages involved in analysing, designing, developing, implementing and evaluating recently published language learning courseware in the context of higher education for B2 ${ }^{2}$ learners of English for Specific Purposes (ESP). The approach underlying this specific educational process, based on developing pedagogicallysound online language learning materials, is known as the ADDIE model, i.e. analysis, design, development, implementation and evaluation (Colpaert, 2013, p.16). The whole project was planned and structured to lay the theoretical foundations and correlate these to each of the development phases in order to deliver and evaluate tailor-made courseware and make it accessible to students at the Technical University of Valencia (Universitat Politècnica de València, UPV). Taking into account the specific educational context and the resources provided by the institution itself is crucial in understanding the process and many of the decisions made during the design process. One of these was to explore the possibilities of including technical language and topics -which require special knowledge to be understood-in the online course and to analyse how students perceived and interacted with it. The findings are discussed in section 6 .

The research questions that are therefore addressed in this paper are the following:

a) Given the students' voluntary enrolment on an upper-intermediate English language subject whilst studying an undergraduate technical degree at UPV, what is their attitude toward studying with a self-access online course?

b) Should an upper-intermediate English language online course for UPV students include technical content relating to their undergraduate degrees?

c) After completing the online course, were these students satisfied with the technical content included?

d) After completing the online course, were they under the impression that their technical vocabulary had improved?

2 The Common European Framework of Reference for Languages (Council of Europe, 2001) equates level B2 to being an independant user. 


\section{Specific research context and field of study}

Student motivation is one of the most decisive goals pursued by language instructors who engage in designing and developing new e-learning content and materials. However, motivation is one of the most difficult aspects to determine because it may be influenced by a wide variety of factors (Keller \& Suzuki, 2004; Liao, 2006; Lim, 2003; Rogers, 2005; Peacock, 1997). As we shall see in section 6 below, in the case of the particular context analysed in this paper, there is clear evidence that the participants have shown a high level of motivation from the very moment they started using the tailor-made courseware, InGenio FCE Online Course. This could be due to the fact that our students strongly believe that their professional expectations can increase if the knowledge of at least one foreign language is added to their specific training due to today's highly demanding society and work system. Other likely reasons explaining why their level of motivation has been high could relate to the online format itself that was used to deliver the materials; the fact that there has always been a tutor monitoring their progress; the possibility of receiving extra training by accessing supplementary and additional materials or participating in voluntary speaking practice sessions (via Skype); because the courseware is embedded in a platform such as InGenio, which is capable of providing automatic assessment, scores and feedback, etc. (Martínez Sáez, 2015).

Apart from the recommendations set forth by the CEFRL concerning the importance of training students so that they can achieve an acceptable level of competence to maintain technical discussions in their own field of specialisation, it has also been proven that narrowing the context and language content down to students' university degrees, disciplines and fields of study and interest has a direct and positive effect in terms of additional motivation.

Therefore, one of the challenges in our design project was to start exploring different alternatives to combine new specific resources with the general language content which had already been integrated into the courseware. Due to the specific features of each field of study, the specific-purpose content necessarily had to be narrowed down to realistic proportions. In order to do this, the authors decided to expand the resources by incorporating specific topics closely relating to two of the undergraduate degrees delivered at UPV, i.e. Aerospace Engineering and Mechanical Engineering, where they themselves were engaged in teaching technical English. The content developed so far dealing with these two fields of engineering have now been integrated into the InGenio FCE Online Course but the large number of different undergraduate (36) and postgraduate (76) degrees ${ }^{3}$ delivered at UPV makes it an unachievable goal to provide each and every one with its own version of specialised-

\footnotetext{
${ }^{3}$ For more information go to http://www.upv.es.
} 
purpose language content in the said B2 level online course. One of the ideas, however, that might be regarded as the best option is to develop a supplementary third module, which would be added to the first two modules comprising the current version of the courseware.

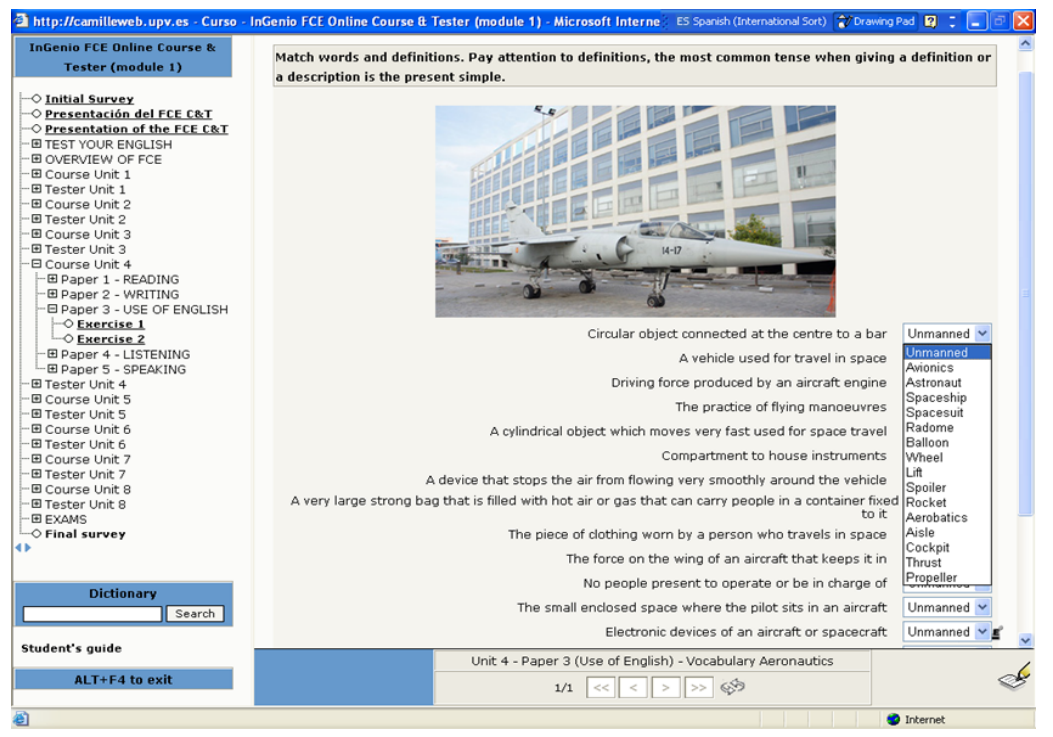

Figure 4. Screenshot of an ESP exercise included in "Course Unit 4".

These considerations have led the authors to explore some of the most representative ideas linked to teaching languages for specific purposes (LSP) in general, and ESP, in particular. Language instructors who work in similar contexts to UPV often focus their research on devising innovative ways of stimulating L2 learning and analysing its impact on acquisition. Great effort is put into class dynamics and trying to keep students' interest alive. Using (educational) technology to channel learning can be a very useful means of fostering transversal skills such as foreign language learning or scientific literacy and reasoning in educational contexts that focus on science and engineering, where students often have very tight schedules. Palalas (2010, p. 238), for one, points out the importance of combining "students' needs and their demanding schedules". According to authors such as White (2009), the aim of using an online channel and format to publish a language course is not only to provide the means to allow easy access to content and information included in that particular course, but also the tools that allow participants to interact and collaborate with fellow online participants. This factor is seen to contribute to the enrichment of the global learning process. As such, in designing the InGenio FCE Online Course, these factors have been taken into account. 


\section{English for Specific Purposes}

The fact of providing students with specific content is also considered as a key factor in stimulating motivation; the more domain-related the content, the more relevant they are considered to be because, as we shall see in the section 6 , students rate the relevance of the materials in connection with how much they think they satisfy their future needs and professional expectations. Chapelle (2003, p.153) points out that, in a context devoted to creating computer-assisted resources, it is especially relevant to make precise and appropriate decisions in every step taken during the design and implementation process; different task-related aspects such as topics and actions, participants, and mode have to be taken into account. When language learning materials are designed to include specialised content in order to make the resources as meaningful as possible for the learner's field of study, there are two main approaches that can be followed. The first one has already been mentioned, i.e. LSP, and the second is CLIL (Content and Language Integrated Learning). In the case addressed in this study, although students have sometimes confessed acquiring knowledge pertaining to their content subjects in the English class, the main approach has always been that of ESP, i.e. putting the main focus on the language and not on the subject matter, which can be seen as an add-on, contrary to what would happen in a typically CLIL approach where the subject matter is the prime focus. To differentiate ESP from general English classes, Räisänen and Fortanet-Gómez (2008, p. 12) highlight that "the main distinction of ESP is that the English taught caters for the needs of the learners in specific disciplines other than the arts and languages". They define its main features as follows:

ESP teaching uses the methodologies and activities of various disciplines it is designed to serve, and it focuses on the language, lexis, grammar, discourses, and genres of those disciplines rather than using the general grammar, learners' dictionaries and general public genres and discourses (Räisänen and Fortanet-Gómez, 2008, p. 12).

Furthermore, the purpose of learning ESP must also be taken into consideration. In general terms ESP is aimed at providing the learner with the tools to "communicate within a specific academic, occupational or professional domain" (Räisänen and Fortanet-Gómez (2008, p. 12). Luzón (2009, p. 13) refers to those specific purposes in a job-related context "where communicative needs change and evolve continuously". Therefore, it is important to "prepare students to become autonomous life-long learners and to be able to continue to access education". According to Luzón, students who develop skills that foster autonomy are more aware of their own learning process and can therefore analyse its strengths and weaknesses; "an approach focusing on the development of autonomy emphasises the importance of the students' own pace and developmental processes, learning styles, self-monitoring and control over the 
learning process" (p. 13).

Technology and online learning has been coupled with ESP in numerous cases. Such is the case of Hussin (2006, p. 91), who states that "as online delivery of courses is adopted by universities world-wide, there is a corresponding need to develop new forms of ESP support teaching". Dashtestani \& Stojković $(2015$, p. 452) also point out that "unlike EFL teachers, ESP teachers should be able to pave the way for students' language learning and at the same time take the specific learning content into consideration. Therefore, technology inclusion in ESP instruction may pose more considerable challenges for ESP teachers and researchers since they should bear in mind that both language and content should be considered in any condition of technology use in ESP instruction." According to Wilkinson (2008, p. 60) "ESP is not a theoretically grounded approach to learning" but "an accumulation of approaches that educators have designed for teaching the language of a set of specific disciplines or purposes to learners who are specialized or specializing in one or more of those disciplines". He explains that, "ESP may be seen as a kind of problem-solving endeavour for the instructor, who has to select and adapt the ESP approach to the knowledge and skill needs required in the particular context" (Ibid., p. 61). Furthermore, he refers to three key features which would be attributable to the concept of ESP and which would be directly connected with the specific language learning resources created and included in the InGenio FCE Online Course so far. The first feature is bearing in mind the students' needs in order to offer a specific response. The second point relates to making use of the underlying methodology and activities of the discipline it serves, and the third and last idea refers to the need to focus on the language (grammar, lexis and register), skills, discourse and genres appropriate to these activities (Ibid. p. 61). This classification, which is widely accepted and also mentioned by Arnó Macià et al. (2006, p. 4) and Räisänen and FortanetGómez (2008, p. 61), was initially provided by Dudley-Evans and St. John (1998, p. 4-5). According to the latter authors, some other defining features should be part of the theoretical foundation of this field of study:

ESP may be related to or designed for specific disciplines; ESP may use, in specific teaching situations, a different methodology from that of general English; ESP is likely to be designed for adult learners, either at a tertiary level institution or in a professional work situation. It could, however, be used for learners at secondary school level; ESP is generally designed for intermediate or advanced students. Most ESP courses assume basic knowledge of the language system, but it can be used with beginners. (Dudley-Evans and St. John (1998, p. 5).

Additionally, Mungra (2009, p. 180) also offers three different defining features that should be taken into account when addressing this particular area: "student 
autonomy, integration with subject teaching and time-flexibility for students". Moreover, computer networking is conceived as a way of contributing toward "a more personalised instruction, something which is extremely important in ESP classes, usually characterised by the heterogeneity of students" (Luzón 2009, p.11). Mungra (2009, p. 203) adds another crucial point to bear in mind: "a thorough understanding of the nature of the technological tools and what they can or cannot do, proper integration in the regular curriculum and finally the appropriate use of human and material resources".

It would also be relevant to mention the concept of English for Academic Purposes, (EAP), which is defined by scholars such as Dressen-Hammouda (2008, p. 75), as "a process-oriented and genre-based approach to writing instruction, whose features are well established within decades of research in applied linguistics, rhetoric and L1/L2 composition studies". She also considers that "approaches to EAP writing instruction thus draw on current understandings of how L1 and L2 students acquire and develop specialized written language skills" (Dressen-Hammouda, 2008, p. 75).

In addition to the concept of EAP, some authors have focused on the similarities between LSP/ESP and CLIL. Such is the case of the use in both contexts of a teaching and learning methodology which is different from the one followed in a general English teaching environment. In both cases, the variation does not only involve changing the language being used and taught, it also implies the application of a welldefined and goal-oriented methodology. Sometimes the boundaries between ESP and CLIL are weaker than might be thought. It is very common in ESP classes for the language instructor, in addition to focussing on the language tuition, to find him or herself explaining and interpreting specific technical concepts prior to these having been explained in the corresponding subject. These and other features could be seen as a reason to foster students' active participation in and awareness of their own learning path (Coyle et al., 2010). Forester (2011, p. 282) also points out that a common feature present in all LSP courses is "a strong emphasis on disciplinary subject matter, both as the goal of and means to language proficiency". Forester also refers to the concept of Content Based Instruction (CBI), which is normally included in the category known as EAP in higher education contexts, and provides us with a list compiled by Brinton et al. (2003) of the benefits and advantages of simultaneously combining language learning and content learning:

1. Language learning requires focus on the actual use learners will make of it.

2. Relevant content takes learner needs and interests into account.

3. CBI builds on previous learner world and content knowledge.

4. Language learning is more effective in real contexts. 
5. Focus on content supports comprehension of new input.

The question about the role played by technology in the entire process has to be taken into account, as well as establishing the benefits or advantages provided once it is implemented as a key tool in this particular learning scenario. Luzón $(2009$, p. 18) pays attention to this idea and states that it is important to frame the question by "taking into account the specific characteristics of ESP learning and teaching and the needs of ESP students" when considering this kind of course. Therefore, it would be necessary to provide a student with all the guidelines and supplementary materials in order to consolidate this online learning process. Some other means to attain this goal would be the following (Luzón, 2009, p.20):

- By offering opportunities for learner control over the instructional path(s) to follow and rendering the possibility of self-repair and changing of options,

- By providing students with tools to plan and monitor their learning process,

- By giving learners control over a variety of media sources, materials and tasks,

- By letting students interact with hypermedia materials which offer different degrees of assistance through online help,

- By facilitating flexible feedback from peers and teachers,

- By encouraging reflective thinking,

- By providing social support for interaction and the sharing of ideas.

Moreover, Arnó et al. (2009, p. 77) also provide materials writers in the field of EAP with a number of guidelines to design and develop highly motivating resources:

- Meaningful tasks: students should be encouraged to perform a meaningful and purposeful task related to their academic needs;

- Academic orientation: The thematic contents of the materials should arouse in students a genuine academic interest and should be based on authentic and varied input from different sources, by combining different media;

- Engagement with topics and tasks: The topics should lend themselves to engagement in critical thinking, discussion and exchange of ideas and opinions;

- Multi-faceted role of the Internet: Not only a medium but also a source of input and a learning objective in itself;

- Genres;

- Exploiting technological resources to promote oral and written production;

- Process-product: the materials and tasks do not only focus on the resulting product but pay special attention to the process;

- Hypertextual structure for different learning routes: Proposing varied and flexible 
activities and making use of the hypertextual structure of the Web;

- Focus on form: In a contextualised manner to aid in the comprehension or production of messages.

These have all been considerations taken into account and, where possible, built into the design criteria of the InGenio FCE Online Course.

\section{InGenio First Certificate in English Online Course}

We shall start by describing the courseware itself. The main goal of the design project was twofold; on the one hand, to create a B2 level English online course, and on the other, to design a preparatory course and speaking practice activities for learners wishing to take the Cambridge First Certificate in English Examination (FCE) ${ }^{4}$. In addition to complying with the specifications set forth in the Common European Framework of Reference for Languages (CEFRL), the courseware was developed following the structure and content of the FCE exam. The CEFRL classifies a B2 level as an independent user who

can understand the main ideas of complex text on both concrete and abstract topics, including technical discussions in his/her field of specialisation. Can interact with a degree of fluency and spontaneity that makes regular interaction with native speakers quite possible without strain for either party. Can produce clear, detailed text on a wide range of subjects and explain a viewpoint on a topical issue giving the advantages and disadvantages of various options. (Council of Europe, 2001, p. 24)

As we can see, this criterion pinpoints the learner's field of specialisation as a determining factor. This, together with the requirements determined by the context in which the course was developed -a technical higher education institution-, led the authors to believe that the resulting courseware should primarily focus on the specific language needs and demands of the target groups, without neglecting the fact that the online course should be appropriate also for use in any higher education context or institution. $^{5}$

The result of the design process led to the publication of the InGenio First Certificate in

4 For further information about this examination, please go to <http://www.cambridgeenglish.org/ exams/first>.

5 Due to the fact that the authoring tool used to develop the course was the one integrated into the InGenio System (Gimeno, 2008 \& 2009a), language instructors from other education settings may modify and adapt the content -should this be necessary- to their own specific language needs and requirements. The resulting material would thus be delivered independently without disrupting the original materials. 
English Online Course ${ }^{6}$. The course comprises two independent modules, each containing 8 units, which are in turn divided into 5 sections (see Fig. 1), paralleling those included in the FCE exam, i.e. reading, writing, use of English, listening and speaking. Each of these is introduced with appropriate theory and explanations followed by the actual exercises. Most of the theoretical content has been embedded in the form of short video recorded presentations.
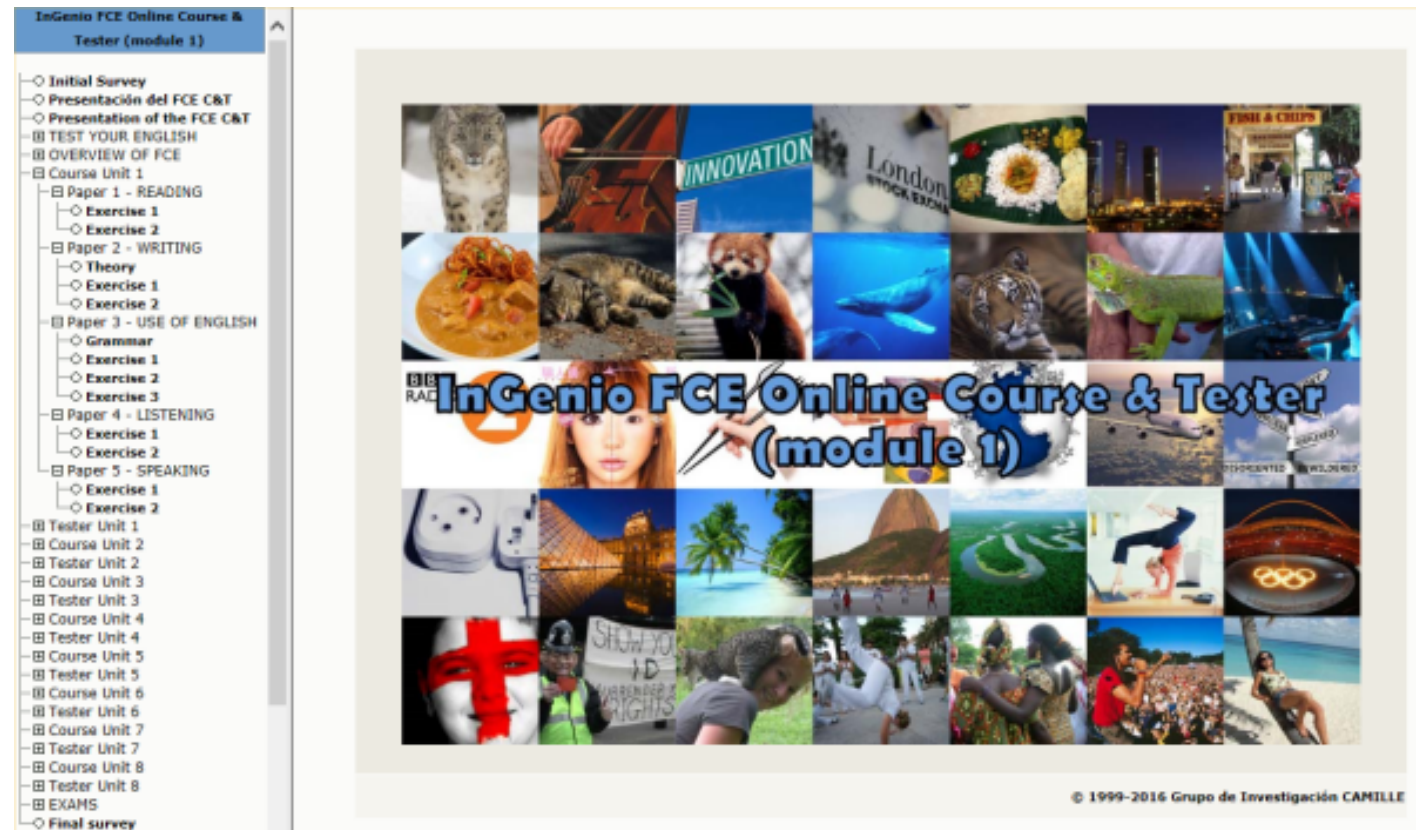

Figure 1. InGenio FCE Online Course \& Tester homepage.

The criteria followed in the design, development and evaluation stages of the course contents were established after a thorough literature review ${ }^{7}$, firstly, on ComputerAssisted Language Learning (CALL) and, secondly, relating to the FCE exam. Ideas and parameters emerging from former research and expert views, together with an analysis of the students' opinions and perceptions after using the materials set the foundations of the courseware. Thus, one of the first steps taken was based on a study of a representative corpus of existing materials in different formats, both printed and digital. By analysing these courses and textbooks, not only the strengths were

6 The InGenio FCE Online Course is supplemented by the InGenio FCE Online Tester, which simulates the FCE exam. The entire courseware is available free of charge to any interested party.

7 The literature review is available from Martínez Sáez, A. (2015). Materiales online para el aprendizaje y la evaluación del inglés: análisis, diseño, propuesta y validación de recursos (Unpublished Doctoral Thesis). Available from the Spanish TESEO PhD database website at <https://www.educacion.gob.es/teseo/irGestionarConsulta.do>. 
depicted and captured, but also the limitations and features that could undergo some sort of improvement. The aim was clear, i.e. to include the most adequate and efficient features in the resulting materials in order to offer more reliable and consistent resources, capable of fulfilling the requirements in terms of language level and better respond to learner needs in terms of specificity of the content (Martínez Sáez, 2015, p. 5).

\section{Assessment and feedback in the InGenio System}

Because the resulting courseware was to be implemented within a blended learning setting, it was important therefore to take special care in providing learner performance assessment as well as automatic and tutor feedback. This was the main reason for choosing to use the InGenio System ${ }^{8}$ for authoring purposes. The resulting courseware offers the user two main assessment modes: self-assessment and tutor assessment, thus allowing the materials to be used autonomously as self-access materials or under the supervision of a tutor via the InGenio online tutoring module (Gimeno et al., 2011). In the former mode, learners carry out the tasks and evaluate their performance and achievements in an independent way, whilst in the latter mode, they have access to corrective feedback provided by the tutor (Fig. 2). In this last case, learners develop a sense of responsibility over their own learning process while receiving help, support and specialised assessment by their tutor (Sevilla Pavón et al., 2011).

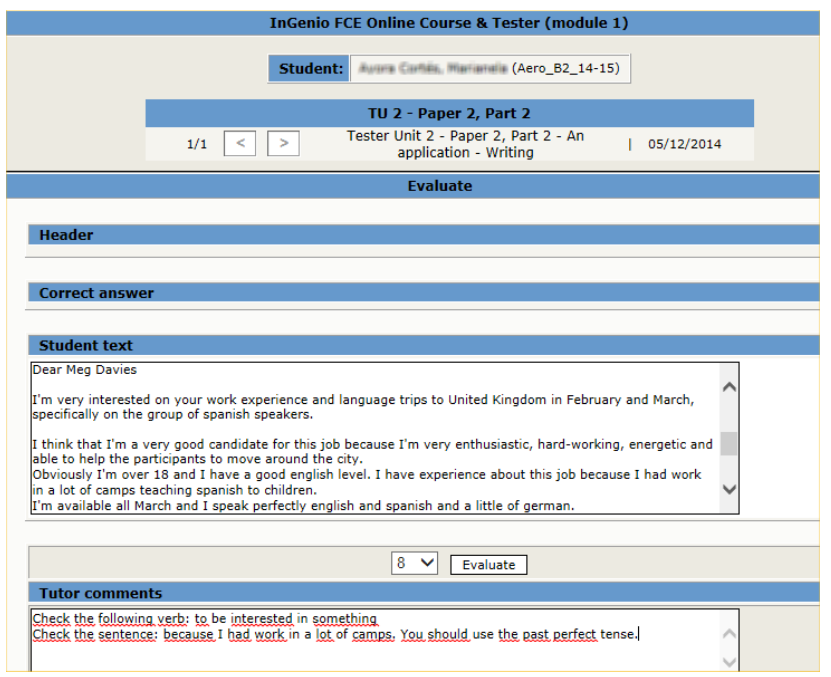

Figure 2. InGenio tutor sample corrective feedback screen.

\footnotetext{
${ }^{8}$ For more information go to <http://camillweb.upv.es/camille>.
} 
In order to aid students working in self-access mode, a number of features such as self-explanatory reference materials, hints to aid exercise completion, performance/ progress reports, audio enhancement of written texts, help files, etc. have been programmed into the courseware (Gimeno Sanz et. al., 2011, p. 552).

The entire development process was performed within the InGenio authoring tool, a tool with a unique capability, i.e. the possibility of enabling materials writers to design specific personalised feedback at programme, exercise and item levels. As Gimeno and de Siqueira (2009, p. 1241) point out "InGenio [...] integrates feedback at three different levels; a) at authoring level, i.e. within the exercise templates to enable language specialists (content providers) to design appropriate feedback for the courseware activities; b) at student level, i.e. ways in which a learner can gain feedback from the courseware by means of automated computer assessment; and c) at tutor level, which enables tutors to provide personalised feedback through the InGenio learning environment".

The exercise templates in the InGenio authoring tool include a default feedback mode providing learners with immediate feedback after completing an exercise, and once the data has been transferred to the server. This default feedback opens up as a separate pop-up window with a random comment and/or recommendation from a list that has been programmed into the system following a number of parameters describing learner performance. Scores themselves are also given, in addition to an indication of the time that has been spent on a given exercise.

Whilst studying with the InGenio FCE Online Course, students can call-up progress reports at any point during the learning process. Upon exercise completion, the data is transferred to the server thus allowing students to monitor their progress during the course of their work. The results are presented in percentages, registering date and time, number of completed exercises, scores, etc., as shown in Figure 3, below.

Marks are automatically averaged by the system in order to give students a final score. When specified in an activity, learners may also upload any type of file (spread sheets, audio files, etc.) onto the server for their tutors to evaluate and assess together with all the other course work (Gimeno Sanz et al., 2011, p. 557). 

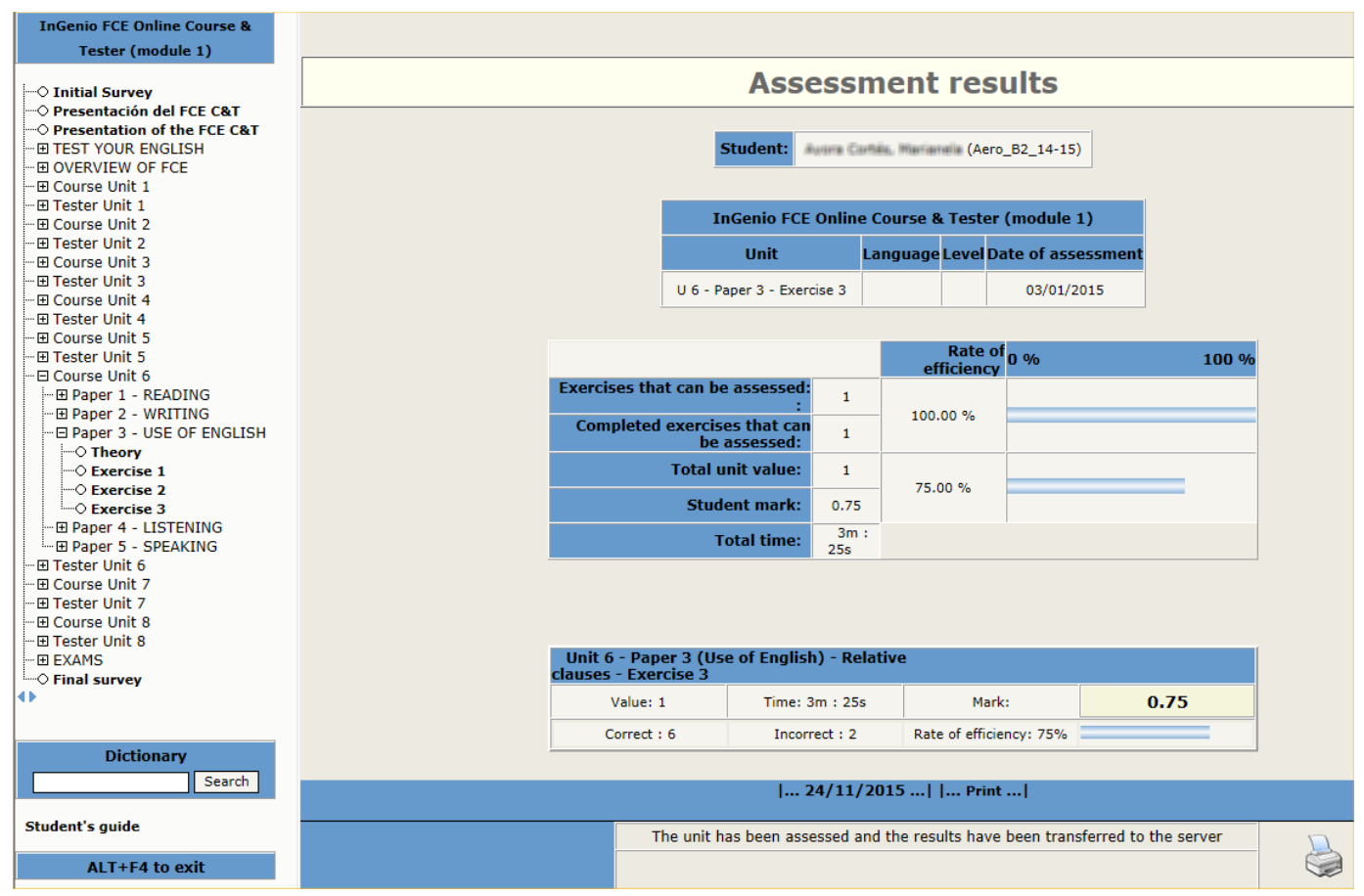

Figure 3. Sample learner progress report.

The versatility of the authoring tool, which is based on the template approach to software authoring (Gimeno Sanz, 2002), allows materials writers (language instructors) to adopt a variety of teaching methodologies, ranging from structural methods to a more communicative approach to language learning. That is, from exercises focussing on grammatical forms to activities simulating authentic interaction. The exercise templates are particularly suitable for designing courses that attempt to acknowledge the fact that a true linguistic competence implies being able to use the language that is appropriate to a given social and cultural context in order to achieve a specific communicative goal. To do this, learners need knowledge of the linguistic forms, meanings and functions for a given context. To achieve this end, InGenio provides a variety of goal-oriented learning strategies in a media-rich electronic environment that supports the study of the target language (Gimeno Sanz, 2009a, p. 87). In line with Luzón's belief (2009, p. 11) that "computer networking provides useful tools to implement approaches which are appropriate for ESP learning, e.g. problem-based learning, case-based learning, cooperative learning, project-based learning", the system used to design the InGenio FCE Online Course 
supports all of these active learning methods, some of which have been built into the course materials. Additionally, "[computer networking] enables students to access a large amount and variety of authentic materials which cater to diverse learning styles and different levels of language competence" (Luzón, 2009: 11).

\section{Survey}

\subsection{Methodology}

Throughout two academic years" ${ }^{9}$, students enrolled on the subject "ComputerAssisted English" (4.5 ECTS during one semester ${ }^{10}$ ) registered for the InGenio FCE Online Course \& Tester (Module 1) and each completed a pre-course survey and a postcourse survey in the form of online questionnaires administered through Google Forms. A total of 95 students submitted the pre-questionnaire and the postquestionnaire after completing the whole course. Student ages ranged from 18 to 23. They were enrolled on one of the following undergraduate engineering degrees at UPV: aerospace, chemical, electrical, electronics, industrial design and mechanical engineering, as well as architecture, industrial management, and business management and administration. The pre-course questionnaire was divided into 5 parts with 66 enquiry items based on a 5-point scale plus 17 open-ended questions. It was designed to seek information relating to the students' attitude toward language learning in general; their command and use of Information and Communications Technologies (ICT); their expectations and preferences in terms of learning English; their preferred learning styles, and their knowledge regarding the FCE exam and the CEFRL. The post-course questionnaire was divided into 5 sections with 54 enquiry items using a 7-point scale and 3 open-ended questions. ${ }^{11}$ These sought to gain insight into the students' perception in terms of courseware features, appropriateness of the content, satisfaction with the self-assessment utilities, perceived improvements in their language skills, satisfaction with the externallyorganised speaking practice activities and, lastly, recommendations for future improvements. Each variable was composed of a number of defining items and analysed qualitatively and quantitatively.

Despite the amount of information retrieved from the two surveys, in what follows we shall only discuss the most relevant findings in relation to the ESP content included in

Throughout 2011-2012 and 2012-2013.

104.5 ECTS is equivalent to 45 teaching hours but the student is expected to devote an additional $50 \%$, making a total of 67.5 hours, which adds up to a sum of 112.5 study hours.

11 Both surveys are available from Martínez Sáez (2015). 
the courseware. This content is mainly present in the reading and listening comprehension sections, which include texts and recordings dealing with specific engineering-related topics, and in the use of English section by paying special attention to technical vocabulary and common expressions or structures that might be helpful in a professional environment.

\subsection{Results}

\subsubsection{Initial questionnaire}

In the initial questionnaire, when the students were asked to rate a number of factors and specify the extent to which they contributed to their motivation to learn English (item $9 \mathrm{~b}$ ), $80 \%$ reported that there is a strong practical need in their lives which drives them to continue their pursuit of improving their level of English. A similarly high number $(77 \%)$ also reported it was the need to travel for work (item 9i) that motivated them, whilst $90 \%$ were motivated by the thought of needing to use the foreign language in the workplace (item 9j), and an overwhelming 100\% stated that their motivation was also due to the belief that improving their foreign language skills would increase their possibilities of finding a better job (item 9k). Out of the 11 options to choose from to answer this question, the vast majority of the students reported motivations related to their future professional lives as the main driving forces toward improving their language and communication skills. These figures therefore provide clear evidence of the participants' expectations about the connection between learning a language and using it in their future professional careers.

(Item 9b)

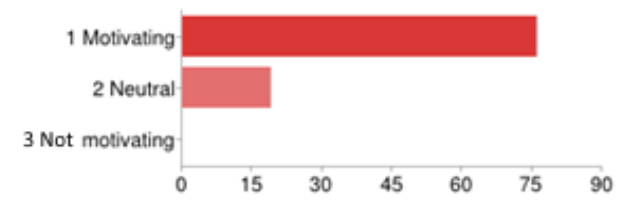

Graph 1. A strong practical need in your life.
(Item 9i)

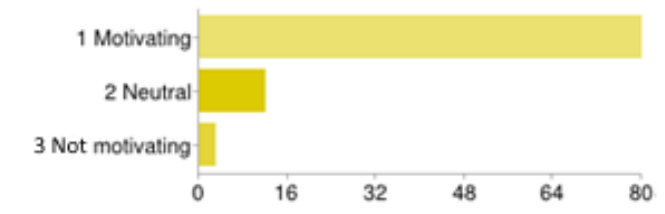

Graph 2. Need to travel for work (current or future). 
(Item 9j)

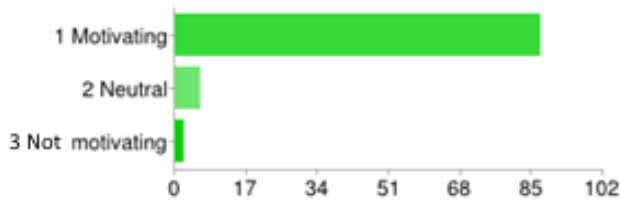

Graph 3. Need to use other languages in the workplace (current or future).
(Item 9k)

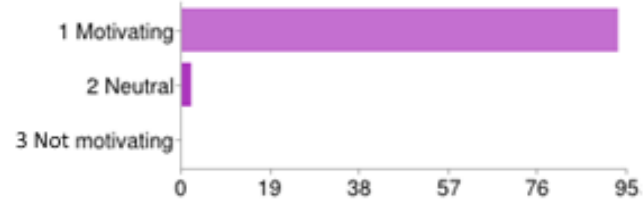

Graph 4. Possibility to get a (better) job.

\subsubsection{Final questionnaire}

The final questionnaire was the tool used to provide evidence that the research conducted in the courseware design project had proven fruitful and that the incorporation of specific criteria, ideas and techniques deriving from the bibliographic references taken into consideration were effective and satisfactory. This is one of the main reasons why students' responses, through the final questionnaire, have been so relevant to validate this part of the research process. The final questionnaire, which was responded by the 95 students who completed the entire course, that is $100 \%$ of the activities, shed light on what the learners' opinions were regarding the actual courseware, its general and specific content, its exercises and activities, its audiovisual aids, its self-assessment reports, etc.

One of the questions in the second part of the questionnaire focused on the validation of the usefulness of the technical content included in the course (question 8). The evaluation provided was once again very positive since $80 \%$ of the students supported the three most favourable options within the 7-point Likert scale provided (37\% rated $5,33 \%$ rated 6 and $10 \%$ rated 7$), 7$ being the highest mark and 1, the lowest. This fact provides evidence that students show a very positive attitude when it comes to assessing the usefulness of including specialised materials as a part of the language learning resources. As we can see in Graph $5^{12}$ below, only $17 \%$ had no opinion and a mere $3 \%$ deemed this content unsatisfactory.

\footnotetext{
${ }^{12}$ In all the graphs below, the vertical axis refers to the number of students (respondents) and the horizontal axis represents the 1-7 Likert scale.
} 
(Question 8)

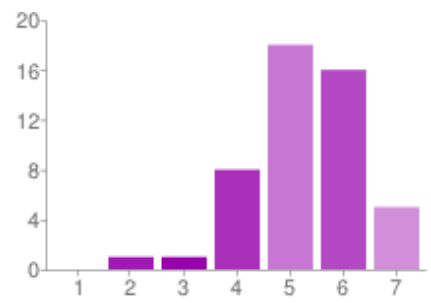

Graph 5. Usefulness of the technical content.

Another question was aimed at measuring the general interest and relevance of the language input included in the materials (question 11), which again was seen as a highly positive aspect; $78 \%$ of the participants supported the three highest options within the scale. A very similar result was observed when they were asked to evaluate the general interest and relevance of the topics (question 12) or the general interest and relevance of the tasks (question 13).

(Question 11)

(Question 12)
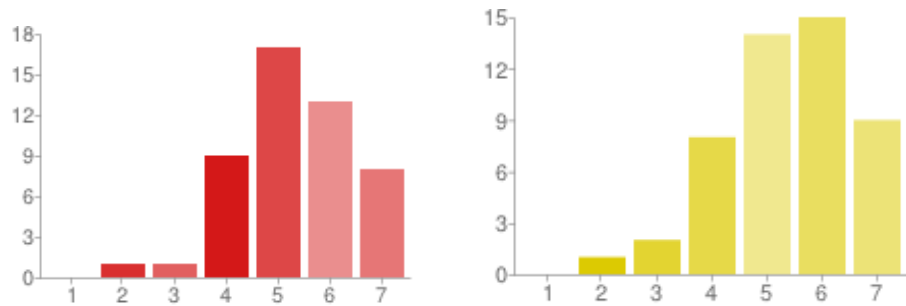

Graph 6. General interest and relevance of the language input.

Graph 7. General interest and relevance of the topics.

(Question 13)

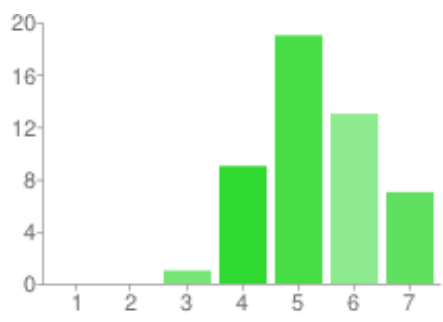

Graph 8. General interest and relevance of the tasks.

When the students were directly asked, in the third section of the questionnaire, how effective the course was when it came to helping them improve their technical vocabulary (question 12), the results were also very similar, as once again, $78 \%$ of the 
participants supported the three most positive answers, as we can see in Graph 9 below.

(Question 12)

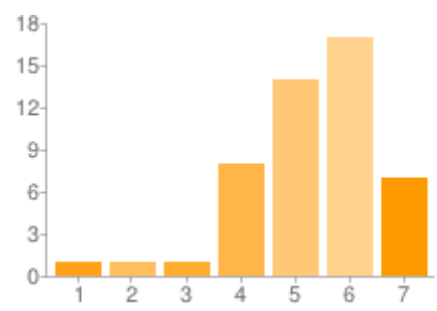

Graph 9. I improved my technical vocabulary.

In the last part of the questionnaire, which dealt with future improvements to be implemented, the percentage of students who showed their support to the proposal of including short videos focused on technical content in English or technical English (question 2) was also very high. In this case, the number of participants who opted for the middle of the scale, i.e. the neutral answer, was higher (27\%) than that in the other questions focusing on ESP, mentioned above. Nevertheless, the positive answers once again indicate that students show a favourable attitude when asked about making the resources relate to specific content directly connected with their own fields of study and specialisation.

(Question 2)

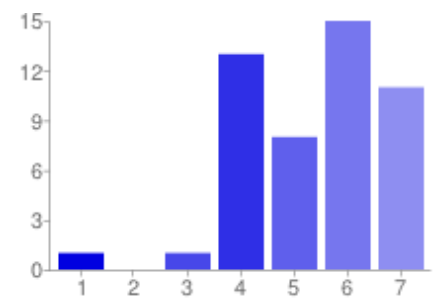

Graph 10. Short videos focused on technical English.

\section{Conclusion}

In order to design the InGenio FCE Online Course several procedures were followed: a) incorporating evidence-based recommendations in CALL design and implementation; b) analysing existing print and digital materials aiming to prepare for the FCE exam; c) following the criteria set forth in the CEFRL in order to comply with the requirements of a B2 level course, and d) incorporating ESP teaching strategies. 
As one of our main objectives in designing the courseware was to satisfy our students' needs regarding technical content in English in order to provide a connection between their undergraduate studies and preparation for their professional careers, having attained a level of satisfaction nearing $80 \%$ in this aspect supported the need to include ESP materials in our online course; a fact which, in our students' view, no doubt gave it an added value. In addition, this high rate of satisfaction was a reward to the authors' extra efforts in designing meaningful ESP materials (Gimeno, 2015, p. 8).

In relation to the research questions referred to in the introduction, enough evidence has been gathered to confirm that a) given the students' voluntary enrolment on an upper-intermediate English language subject whilst studying an undergraduate technical degree at UPV, their attitude toward studying with a self-access online course was very positive both at the outset and after completing the whole course; $b$ ) the learners appreciated and found value in the designers having included technical content connected with their undergraduate degrees; $c$ ) the students were highly satisfied with the technical content included (topics and vocabulary); and d) they were under the impression that their technical vocabulary had improved considerably.

Aiming to increase learner motivation has played a predominant role in the entire research and development process underlying the design and publication of the InGenio FCE Online Course. As previously mentioned, sometimes motivation can be seen as a default feature which is already a part of the participants' personality. On other occasions, however, students need to overcome the fears caused by different and varied factors, such as previous failure, mere misinformation or simply lack of interest caused by the inadequacy of the materials being used (Martínez Sáez, 2015, p. 580). In these cases, further research is required, aimed at exploring how a language instructor or designer of new materials can contribute to the process and how technology can play a key role. Technology is usually considered a powerful tool, capable of helping overcome difficulties and obstacles that other traditional resources and approaches would not be able to deal with. Likewise, materials writers and the instructors who integrate these tools into their teaching practice have to find the best way and the most effective methodology to be able to achieve those initial goals.

\section{About the authors}

Ana Gimeno Sanz holds a PhD in English Philology, awarded by the University of Valencia, and is Associate Professor in English Language at the Department of Applied Linguistics, Universidad Politécnica de Valencia, Spain. She is leader of the 
CAMILLE R\&D Group devoted to Computer-Assisted Language Learning and is former president of EUROCALL, the European Association for Computer-Assisted Language Learning (2005-2011). She serves on the Editorial Boards of two of the major CALL journal, ReCALL (CUP) and the Computer Assisted Language Learning International Journal (Taylor \& Francis), as well as being editor-in-chief of EUROCALL'S online scientific journal, The EUROCALL Review. She is currently Chair of the WorldCALL Steering Committee.

Antonio Martínez Sáez graduated in English Studies and in Translation and Interpreting Studies at the Universitat de València. He holds a PhD in Applied Linguistics, awarded by the Universitat Politècnica de València, and is lecturer in English Language at the Department of English Studies, Universidad Autónoma de Madrid, Spain. He has been holder of a four-year research grant awarded by the Valencian Regional Government and a member of the CAMILLE Research Group (Department of Applied Linguistics, UPV). He has attended national and international conferences, is particularly interested in and has published several articles and reviews on Computer-Assisted Language Learning and Testing.

\section{Acknowledgements}

The authors would like to thank the Valencian Regional Government (Generalitat Valenciana) for funding the 4-year pre-doctoral research scholarship awarded to Antonio Martínez Sáez for the development and completion of his PhD, which was successfully defended on $11^{\text {th }}$ December 2015.

\section{Article history}

Paper received: $1^{\text {st }}$ February 2016

Paper received in revised form and accepted for publication: $28^{\text {th }}$ March 2016

\section{References}

Arnó Macià, E., Soler Cervera, A., \& Rueda Ramos, C. (2006). The role of Information Technology in languages for specific purposes: Some central issues. In E. Arnó Macià, A. Soler Cervera \& C. Rueda Ramos (Eds.), Information Technology in Languages for Specific Purposes: Issues and prospects (pp. 3-13). New York: Springer. 
Brinton, D., Snow, A., \& Wesche, M. (2003). Content-based second language instruction. Ann Arbor, MI: University of Michigan Press.

Chapelle, C. (2003). English language learning and technology: lectures on Applied Linguistics in the age of Information and Communication Technology. Amsterdam: John Benjamins Publishing Co.

Colpaert, J. (2013). The role and shape of speech technologies in well-designed language learning environments. In P. Badin et al. (Eds.), Proceedings of SLaTE 2013 - Interspeech 2013 Satellite workshop on speech and language technology in education (pp. 16-19). Grenoble, France.

Council of Europe (2001). Common European Framework of Reference for Languages. Cambridge: Cambridge University Press.

Coyle, D., Hood, P., \& Marsh, D. (2010). CLIL: Content and Language Integrated Learning. Cambridge: Cambridge University Press.

Dashtestani, R., \& Stojković, N. (2015). The use of technology in English for Specific Purposes (ESP) instruction: A literature review. The Journal of Teaching English for Specific and Academic Purposes, 3(3), 435-456.

Dressen-Hammouda, D. (2008). Aligning EAP writing pedagogies across European universities: A case study from France. In I. Fortanet-Gómez \& C. A. Räisänen (Eds.), ESP in European higher education: Integrating language and content (pp. 75-96 ). Amsterdam: John Benjamins Publishing Co.

Dudley-Evans, T., \& St. John, M. (1998). Developments in English for specific purposes: A multidisciplinary approach. Cambridge: Cambridge University Press.

Forester, L. (2011). Connecting with CALL: Using technology to connect language learners with other disciplines. In N. Arnold \& L. Ducate (Eds.), Present and future promises of CALL: From theory and research to new directions in language learning (pp. 281-310 ). San Marcos, TX: CALICO Publications.

Gimeno Sanz, A. (2015). Analysing learner attitudes to learning ESP online with the InGenio Content Management System. In Proceedings of the ESP Conference 2015: Synergies of Language Learning (pp. 1-8). Serbia: University of Niš.

Gimeno Sanz, A., Martínez Sáez, A., Sevilla Pavón, A., \& de Siqueira Rocha, J.M. (2011). Fostering autonomy in pedagogically sound e-learning environment for learners of English for specific purposes. In Maruenda, S. \& B. Clavel (Eds.), Multiple Voices in Academic and Professional Discourse: Current Issues in Specialised Language Research, Teaching and New Technologies (pp. 547-560). Cambridge: Cambridge Scholar Publishing.

Gimeno Sanz, A. (2009a). Online courseware design and delivery: The InGenio authoring system. In I. González-Pueyo, C. Foz Gil, M. Jaime Siso \& M.J. Luzón Marco (Eds.), Teaching academic and professional English online (pp. 83-105). Bern: Peter Lang.

Gimeno Sanz, A. (2009b). How can CLIL benefit from the integration of Information and Communications Technologies? In M. L. Carrió-Pastor (Ed.), Content and Language 
Integrated Learning: Cultural diversity (pp. 77-106 ). Bern: Peter Lang.

Gimeno Sanz, A., \& de Siqueira, J.M. (2009). Designing feedback to support language acquisition using the InGenio authoring tool. In H. Uzunboylu \& N. Cavus (Eds.), Procedia - Social and Behavioral Sciences, 1(1): 1239-1243. Proceedings of the 1st World Conference on Educational Sciences 2009. Science Direct. Elsevier. doi:10.1016/j.sbspro.2009.01.221

Gimeno Sanz, A. (2008). InGenio: A dedicated CALL authoring shell, content manager and courseware delivery platform. Aprendizaje de lenguas asistido por ordenador: herramientas de autor para el desarrollo de cursos a través de la web (pp. 93-117). Valencia: Editorial Universidad Politécnica de Valencia.

Gimeno Sanz, A. (2002). Call software design and implementation: the template approach. Valencia: Editorial de la Universidad Politécnica de Valencia.

Hussin, V. (2006). Uncovering tasks and texts - Teaching ESP through online workshops. In E. Arnó Macià, A. Soler Cervera \& C. Rueda Ramos (Eds.), Information Technology in languages for specific purposes: Issues and prospects (91-104). New York: Springer.

Keller, J., \& Suzuki, K. (2004). Learner motivation and e-learning design: A multinationally validated process. Journal of Educational Media, 29(3), 229-239.

Liao, L. F. (2006). A flow theory perspective on learner motivation and behavior in distance education. Distance Education, 27(1), 45-62.

Lim, D. H., \& Kim, H. (2003). Motivation and learner characteristics affecting online learning and learning application. Journal of Educational Technology Systems, 31(4), 423-439.

Luzón, M. J. (2009). Learning academic and professional English online: Integrating technology, language learning and disciplinary knowledge. In I. González-Pueyo, C. Foz Gil, M. Jaime Siso \& M. J. Luzón Marco (Eds.), Teaching academic and professional English online (pp. 1133). Bern: Peter Lang.

Martínez Sáez, A. (2015). Materiales online para el aprendizaje y la evaluación del inglés: análisis, diseño, propuesta y validación de recursos (Doctoral Thesis. Universidad Politécnica de Valencia). Available from the Spanish TESEO PhD database website at https://www.educacion.gob.es/teseo/irGestionarConsulta.do.

Mungra, P. (2009). Online delivery of a writing course: Description of a blended language course integrated into Medicine. In I. González-Pueyo, C. Foz Gil, M. Jaime Siso \& M. J. Luzón Marco (Eds.), Teaching academic and professional English online (pp. 181-208 ). Bern: Peter Lang.

Palalas, A. (2010). ESP for busy adult students: Is the blend of mobile and online learning the answer? In A. Gimeno (Ed.), New trends in Computer-Assisted Language Learning: Working together (pp. 237-242). London: Macmillan ELT.

Peacock, M. (1997). The effect of authentic materials on the motivation of EFL learners. ELT Journal, 51(2), 144-156.

Räisänen, C., \& Fortanet-Gómez, I. (2008). The state of ESP teaching and learning in Western European higher education after Bologna. In I. Fortanet-Gómez \& C. A. Räisänen (Eds.), ESP 
in European higher education: Integrating language and content (pp. 11-51). Amsterdam: John Benjamins Publishing Co.

Rodgers, D. L., \& Withrow-Thorton, B. J. (2005). The effect of instructional media on learner motivation. International Journal of Instructional Media, 32(4), 333-342.

Sevilla Pavón, A., Martínez Sáez, A., \& de Siqueira Rocha, J. M. (2011). In S. Thouësny \& L. Bradley (Eds.), Second language teaching and learning with technology: Views of emergent researchers (pp. 45-69). Dublin: Research-publishing.net.

White, C. (2009). Language learning in distance education. Cambridge: Cambridge University Press.

Wilkinson, R. (2008). Locating the ESP space in problem-based learning: English-medium degree programmes from a post-Bologna perspective. In I. Fortanet-Gómez \& C. A. Räisänen (Eds.), ESP in European higher education: Integrating language and content (pp. 5573). Amsterdam: John Benjamins Publishing Co. 